\title{
Resveratrol Butyrate Esters Inhibit Obesity Caused by Perinatal Exposure to Bisphenol A in Female Offspring Rats
}

\author{
Ming-Kuei Shih ${ }^{1} \mathbb{D}$, You-Lin Tain ${ }^{2,3}{ }^{\mathbb{D}}$, Yu-Wei Chen ${ }^{4}$, Wei-Hsuan Hsu ${ }^{5} \mathbb{D}$, Yao-Tsung Yeh ${ }^{6,7}$, Sam K. C. Chang ${ }^{8,9}$, \\ Jin-Xian Liao ${ }^{10}$ and Chih-Yao Hou ${ }^{10, *(D)}$
}

Citation: Shih, M.-K.; Tain, Y.-L.; Chen, Y.-W.; Hsu, W.-H.; Yeh, Y.-T.; Chang, S.K.C.; Liao, J.-X.; Hou, C.-Y. Resveratrol Butyrate Esters Inhibit Obesity Caused by Perinatal Exposure to Bisphenol A in Female Offspring Rats. Molecules 2021, 26, 4010. https://doi.org/10.3390/ molecules 26134010

Academic Editors: Thomas Netticadan, Jeffrey Wigle and Pema Raj

Received: 2 June 2021

Accepted: 28 June 2021

Published: 30 June 2021

Publisher's Note: MDPI stays neutral with regard to jurisdictional claims in published maps and institutional affiliations.

Copyright: (c) 2021 by the authors. Licensee MDPI, Basel, Switzerland. This article is an open access article distributed under the terms and conditions of the Creative Commons Attribution (CC BY) license (https:// creativecommons.org/licenses/by/ $4.0 /)$.
1 Graduate Institute of Food Culture and Innovation, National Kaohsiung University of Hospitality and Tourism, No.1, Songhe Rd., Xiaogang Dist., Kaohsiung City 812, Taiwan; mkshih@mail.nkuht.edu.tw

2 Department of Pediatrics, Kaohsiung Chang Gung Memorial Hospital and Chang Gung University College of Medicine, Kaohsiung 833, Taiwan; tainyl@hotmail.com

3 Institute for Translational Research in Biomedicine, Kaohsiung Chang Gung Memorial Hospital and Chang Gung University College of Medicine, Kaohsiung 833, Taiwan

4 Department of Medicine, Chang Gung University, Linkow 333, Taiwan; naosa720928@gmail.com

5 Department of Food Safety/Hygiene and Risk Management, College of Medicine, National Cheng Kung University, Tainan 704, Taiwan; whhsu@mail.ncku.edu.tw

6 Aging and Disease Prevention Research Center, Fooyin University, Kaohsiung 831, Taiwan; glycosamine@yahoo.com.tw

7 Biomed Analysis Center, Fooyin University Hospital, Pingtung 928, Taiwan

8 Experimental Seafood Processing Laboratory, Costal Research and Extension Center, Mississippi State University, Starkville, MS 39567, USA; schang@fsnhp.msstate.edu

9 Department of Food Science, Nutrition and Health Promotion, Mississippi State University, Starkville, MS 39762, USA

10 Department of Seafood Science, National Kaohsiung University of Science and Technology, Kaohsiung 824, Taiwan; j0920181@gmail.com

* Correspondence: chihyaohou@gmail.com; Tel.: +886-985300345; Fax: +886-7-3640364

\begin{abstract}
Resveratrol butyrate esters (RBE) are derivatives of resveratrol (RSV) and butyric acid and exhibit biological activity similar to that of RSV but with higher bioavailability. The aim of this study was designed as an animal experiment to explore the effects of RBE on the serum biochemistry, and fat deposits in the offspring rats exposed to bisphenol A (BPA), along with the growth and decline of gut microbiota. We constructed an animal model of perinatal Bisphenol A (BPA) exposure to observe the effects of RBE supplementation on obesity, blood lipids, and intestinal microbiota in female offspring rats. Perinatal exposure to BPA led to weight gain, lipid accumulation, high levels of blood lipids, and deterioration of intestinal microbiota in female offspring rats. RBE supplementation reduced the weight gain and lipid accumulation caused by BPA, optimised the levels of blood lipids, significantly reduced the Firmicutes/Bacteroidetes (F/B) ratio, and increased and decreased the abundance of S24-7 and Lactobacillus, respectively. The analysis of faecal short-chain fatty acid (SCFA) levels revealed that BPA exposure increased the faecal concentration of acetate, which could be reduced via RBE supplementation. However, the faecal concentrations of propionate and butyrate were not only significantly lower than that of acetate, but also did not significantly change in response to BPA exposure or RBE supplementation. Hence, RBE can suppress BPA-induced obesity in female offspring rats, and it demonstrates excellent modulatory activity on intestinal microbiota, with potential applications in perinatological research.
\end{abstract}

Keywords: resveratrol butyrate esters (RBEs); perinatal exposure; obesity; bisphenol A (BPA); Firmicutes/Bacteroidetes (F/B) ratio

\section{Introduction}

Bisphenol A (BPA) exposure is the most prevalent in the environment [1]. Rahman et al. (2021) summarized several confounding factors that may be directly or indirectly related to human BPA exposure and detailed the disparities between scientifically derived 
safe dosages of BPA and those designated as "safe" by government regulatory agencies [2]. Exposure to BPA during early development has been associated with the prevalence of various cardiometabolic diseases [3] including obesity [4,5], metabolic syndrome [6], type 2 diabetes $[5,7]$, and cardiovascular diseases [5,8]. The toxicokinetic studies of laboratory animals and humans after oral ingestion of BPA have similar results. BPA is rapidly absorbed from the gastrointestinal tract and undergoes first-pass conjugation to BPAglucuronide (BPA-gluc) and BPA-sulfate (BPA-sulfate), which are biologically inactive metabolites [9-12]. The studies after oral intake of BPA or high-BPA diet in humans are consistent with animal data, confirming that the internal exposure of unbound BPA is lower after oral exposure, and BPA-gluc is the main metabolite [13-18].

Growing evidence suggests that, due to the phenolic structure of BPA, it interacts with estrogen receptors and acts as either agonist or antagonist via estrogen receptor-dependent signaling pathways [19-22]. Previous studies have demonstrated the developmental origins of the health and disease $(\mathrm{DOHaD})$ hypothesis $[23,24]$, which highlights the links between the periconceptual, foetal, and early infant phases of life and the subsequent development of adult obesity and related metabolic disorders $[25,26]$. The lipophilicity of BPA facilitates its entry through placental and blood-brain barriers into the foetus, where it triggers oxidative damage and nerve injury in the brain, thereby affecting brain development and causing permanent foetal brain injury [27]. In addition, previous animal studies have demonstrated that maternal and foetal exposure to BPA also damages the immune system and affects the balance of intestinal microbiota in the offspring $[28,29]$. There is little doubt that poor diet and lack of exercise contribute to the obesity epidemic; recent studies have identified an estrogen endocrine disrupter chemical BPA that may act as an environmental obesogen and either directly or indirectly influence fat accrual [30]. The plausible explanation may involve sex hormones, genomic and non-genomic pathway involving nuclear estrogen receptors, differing developmental pattern and/or epigenetic influence [31-33]. Somm et al. [34] reported that exposure to $70 \mu \mathrm{g} / \mathrm{kg} /$ day of BPA during pregnancy can upregulate the expression of PPAR $\gamma, \mathrm{C} / \mathrm{EBP} \alpha$, and LPL in abdominal adipocytes of adult female rats. In addition, body weight only increased in females, in which parametrial white adipose tissue (PWAT) weight increased about threefold. Resveratrol (RSV) can prevent BPA-induced metabolic abnormalities in offspring. Darby et al. (2019) showed that RSV can improve the placental blood flow by increasing the bioavailability of $\mathrm{NO}$, can increase the activity of antioxidant enzymes in foetuses and placentas, and can reduce the rates of inflammation and cell death in placentas to ensure adequate foetal nutrition [35]. Therefore, RSV is often employed in the treatment of metabolic abnormalities and oxidative stress attributed to gestational diabetes in offspring.

The pharmacokinetic study reported by Huang et al. (2019) showed that the blood concentration of RSV peaked within 0.5 to $2 \mathrm{~h}$ after oral administration, followed by a rapid decline [36], indicating that RSV is unable to induce adequate pharmacological responses in pregnant women; hence, it is not an ideal clinical drug. We reported novel resveratrol butyrate esters (RBEs) and indicated the esterification of RSV with butyrate that contained RSV ( 17.1\%), RBE monoester ( $47.1 \%)$, and RBE diester $(\sim 35.0 \%)$, which also had better hydrogen peroxide scavenging activity than RSV [37] and could effectively inhibit fattyacid-induced lipid accumulation in HepG2 cells, with effects similar to those of RSV, but achieved at a lower dose level [38]. Butyrate, one of the short-chain fatty acids (SCFAs), can selectively promote the growth of beneficial bacteria that improve the intestinal barrier's function [39]. As RBE can be catabolised into RSV and butyrate in the body [40], we also attempted to further increase the concentration of butyrate in the intestinal tract to protect the colonic epithelial cells and nervous tissue in the brain.

Numerous studies have confirmed that intestinal microbiota and obesity are closely associated with metabolic abnormalities in hosts [41]. For example, the Firmicutes/ Bacteroidetes (F/B) ratio, which is related to obesity, is lower in obese individuals than in normal individuals [42-45]. 
To date, there are still no obesity-related perinatological studies of RBE. Although the sex-specific effects of BPA are well documented, including the differential susceptibility of males and females to different doses of BPA [31,32,46-49], the underlying mechanism remains unclear [47]. Therefore, we performed perinatal BPA exposure studies to observe the effects of RBE supplementation on obesity-related indicators and intestinal microbiota in female rat offspring to better understand the potential applications of RBE.

\section{Results}

2.1. Changes in Body Weight, Abdominal Lipid Weight, Plasma Biochemical Markers, and Adipose Tissues in Female Offspring Rats

Table 1 shows that the perinatal exposure to BPA led to obesity in female offspring with $16 \%, 77 \%$, and $70 \%$ increases in their body weight (BW), abdominal lipid weight $(\mathrm{LW})$, and relative lipid weight (RLW) $[(\mathrm{BPA} / \mathrm{CN})-1]^{*} 100 \%$, respectively. In addition, the perinatal exposure to BPA also affected their blood biochemical and hormonal compositions with $67 \%, 16 \%, 30 \%$, and $25 \%$ increases and a $49 \%$ decrease in their TG, TC, LDL, leptin, and HDL levels, respectively. These negative effects of perinatal exposure to BPA on female offspring rats were reversed via RBE supplementation, which not only prevented obesity and increased blood lipids and relevant hormones in a dose-dependent manner, but also reduced these health parameters to the same levels or to even lower levels than those observed in the $\mathrm{CN}$ group. For example, the statistically significant differences between the $\mathrm{B}+\mathrm{R} 30$ group and the CN group with respect to LW, RLW, TC, and LDL were favourable. In addition, R30 led to an $11 \%$ weight gain $\left.((\mathrm{R} 30 / \mathrm{CN})-1)^{*} 100 \%\right)$ and $19 \%$ increase in the blood leptin level $\left.((\mathrm{R} 30 / \mathrm{CN})-1)^{*} 100 \%\right)$ in female offspring rats but did not significantly alter their LW and RLW compared to those observed in the CN group. Hence, the body weight gain caused by R30 was not directly associated with increased body fat or leptin concentration.

Table 1. Body weight, lipid weight, and plasma biochemical parameters of female offspring rats.

\begin{tabular}{|c|c|c|c|c|c|}
\hline Groups & $\mathrm{CN}$ & $\mathbf{R} 30$ & BPA & B+R10 & $\mathrm{B}+\mathbf{R} 30$ \\
\hline Body weight (g) & $171.3 \pm 2.7^{a}$ & $189.9 \pm 8.2^{b}$ & $198.1 \pm 9.8^{b}$ & $184.4 \pm 6.3^{\mathrm{ab}}$ & $172.9 \pm 2.0^{\mathrm{a}}$ \\
\hline Lipid weight $(g) *$ & $2.21 \pm 0.34^{\mathrm{a}}$ & $1.45 \pm 0.14^{\mathrm{a}}$ & $3.91 \pm 0.88^{b}$ & $2.17 \pm 0.43^{\mathrm{a}}$ & $1.32 \pm 0.42^{\mathrm{a}}$ \\
\hline $\begin{array}{l}\text { Relative lipid } \\
\text { weight (\%) }\end{array}$ & $1.29 \pm 0.25^{a}$ & $0.81 \pm 0.04^{b}$ & $2.20 \pm 0.30^{\mathrm{c}}$ & $1.25 \pm 0.18^{a}$ & $0.91 \pm 0.26^{a}$ \\
\hline $\mathrm{TG}(\mu \mathrm{g} / \mathrm{mL})$ & $79.5 \pm 10.6^{a}$ & $77.0 \pm 10.7^{a}$ & $132.0 \pm 2.0^{b}$ & $105.0 \pm 5.0^{c}$ & $68.3 \pm 5.5^{\mathrm{a}}$ \\
\hline $\mathrm{TC}(\mu \mathrm{g} / \mathrm{mL})$ & $1095.2 \pm 59.9^{a}$ & $1167.2 \pm 33.3^{a b}$ & $1260.5 \pm 38.7^{\mathrm{c}}$ & $1281.4 \pm 17.2^{\mathrm{c}}$ & $1209.2 \pm 9.2^{b c}$ \\
\hline HDL $(\mu \mathrm{g} / \mathrm{mL})$ & $143.5 \pm 15.8^{a b}$ & $144.1 \pm 12.5^{\mathrm{ab}}$ & $73.7 \pm 2.6^{\mathrm{c}}$ & $164.2 \pm 5.3^{\mathrm{a}}$ & $134.2 \pm 23.3^{b}$ \\
\hline $\mathrm{LDL}(\mu \mathrm{g} / \mathrm{mL})$ & $667.1 \pm 26.7^{a}$ & $498.3 \pm 5.3^{b}$ & $870.2 \pm 40.3^{c}$ & $536.8 \pm 7.9^{d}$ & $482.8 \pm 22.6^{a}$ \\
\hline Leptin (pg/mg) & $350.9 \pm 31.6^{a}$ & $419.4 \pm 6.0^{b}$ & $437.6 \pm 17.9^{b}$ & $344.2 \pm 12.3^{a}$ & $355.5 \pm 11.2^{\mathrm{a}}$ \\
\hline
\end{tabular}

a-d Values with different letters are specific to each group and show significant differences $(p<0.05)$. CN = control group; R30 = group administered with $30 \mathrm{mg} / \mathrm{kg} /$ day of RBE; BPA = group administered $50 \mu \mathrm{g} / \mathrm{kg} /$ day of bisphenol A; BPA+R10 = group administered with $10 \mathrm{mg} / \mathrm{kg} /$ day of RBE and bisphenol A; BPA+R30 = group administered with $30 \mathrm{mg} / \mathrm{kg} /$ day of RBE and bisphenol A; * abdominal LW;

${ }^{\#}$ Relative lipid weight (\%): (abdominal lipid weight/BW) *100\%. Data are expressed as means \pm SD $(n=4-8)$.

Figures 1 and 2 show the stained sections of white adipose tissue and subcutaneous tissue from the abdomens of female offspring rats. Figure 1 shows that BPA-exposed female offspring rats had significantly abnormally large adipocytes, which were reduced via BRE supplementation (B+R10 and B+R30 groups), indicating that RBE could reduce the BPA-induced adipocyte accumulation in offspring in a dose-dependent manner. In contrast, the staining of the subcutaneous tissue sections of female offspring rats (Figure 2) revealed that, in the BPA/RBE groups, the thickness of the subcutaneous tissue was significantly increased by BPA and could be reduced by RBE. Female offspring rats in the R30 group had slightly thicker subcutaneous tissues than those in the CN group. Figures 1 and 2 generally show similar results. Additionally, the results in Figures 1 and 2 are consistent with the increases in LW and BW demonstrated in Table 1. 

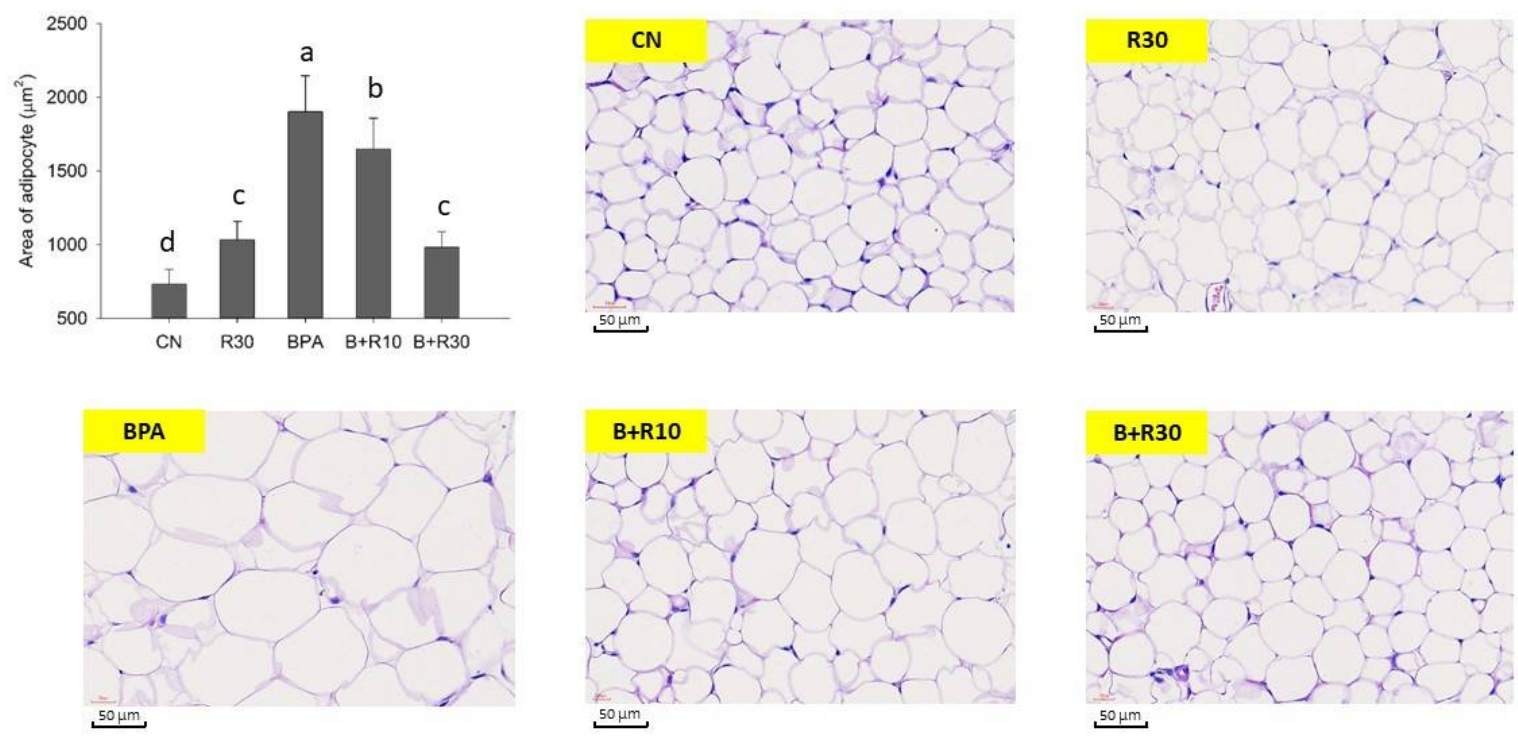

Figure 1. Representative pictures of lipid sections stained with haematoxylin and eosin (H\&E) and examined under a microscope. ${ }^{a-d}$ Values with different letters are specific to each group and show significant differences $(p<0.05)$. $\mathrm{CN}=$ control group; $\mathrm{R} 30$ = group administered with $30 \mathrm{mg} / \mathrm{kg} /$ day of RBE; BPA = group administered with $50 \mu \mathrm{g} / \mathrm{kg} / \mathrm{day}$ of bisphenol $\mathrm{A} ; \mathrm{BPA}+\mathrm{R} 10=$ group administered with $10 \mathrm{mg} / \mathrm{kg} /$ day of $\mathrm{RBE}$ and bisphenol A; BPA+R30 = group administered with $30 \mathrm{mg} / \mathrm{kg} /$ day of RBE and bisphenol A. Data are expressed as mean $\pm \mathrm{SD}(n=4-8)$.
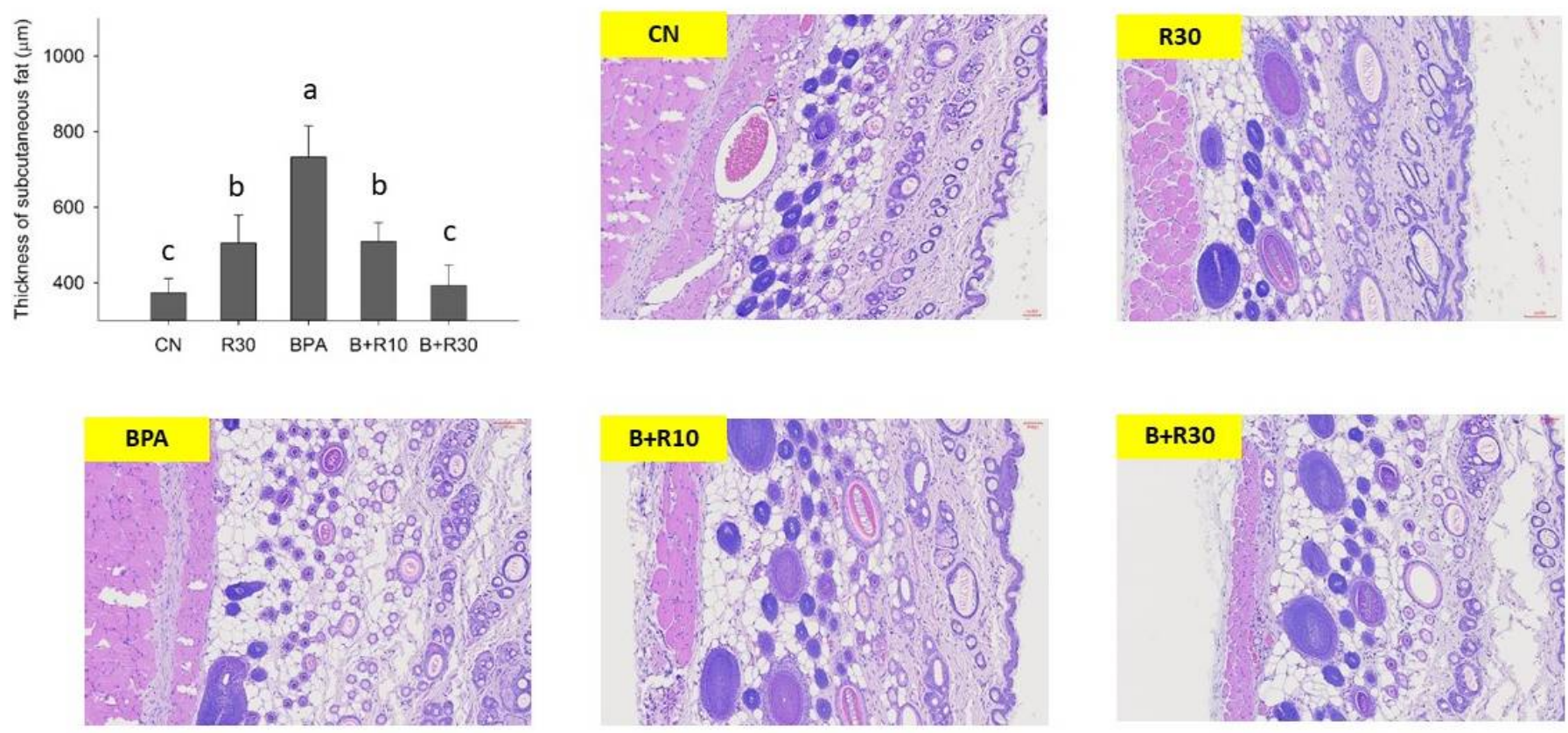

Figure 2. Representative images of subcutaneous tissue sections stained with haematoxylin and eosin (H\&E) and examined under a microscope. ${ }^{\mathrm{a}-\mathrm{c}}$ Values with different letters are specific to each group and show significant differences $(p<0.05)$. $\mathrm{CN}=$ control group; $\mathrm{R} 30$ = group administered with $30 \mathrm{mg} / \mathrm{kg} /$ day of RBE; BPA = group administered $50 \mu \mathrm{g} / \mathrm{kg} / \mathrm{day}$ of bisphenol A; BPA+R10 = group administered with $10 \mathrm{mg} / \mathrm{kg} /$ day of $\mathrm{RBE}$ and bisphenol A; BPA+R30 = group administered with $30 \mathrm{mg} / \mathrm{kg} /$ day of RBE and bisphenol A. Data are expressed as means $\pm \operatorname{SD}(n=4-8)$.

Therefore, the above data suggest that obesity in female offspring rats is indeed attributed to BPA and can be significantly suppressed via RBE supplementation. This study, which explored RBE supplementation during the perinatal period, is also the first report on the inhibitory activity of RBE against BPA-induced obesity and its effects on routine blood biochemical markers in offspring. 


\subsection{Changes in Intestinal Microbiota and Faecal Concentrations of SCFAs in Female Offspring Rats}

In this study, we observed changes in the intestinal microbiota and faecal concentrations of SCFAs in female offspring rats. Figure $3 \mathrm{~A}$ shows that the F/B ratios in CN, BPA, and $\mathrm{R} 30$ were $1.45,1.40$, and 0.82 , respectively, and those in $\mathrm{BPA}+\mathrm{R} 10$ and $\mathrm{BPA}+\mathrm{R} 30$ were 1.21 and 0.86 . Therefore, there was a significant dose-dependent increase in the abundance of Bacteroidetes and a decrease in the abundance of Firmicutes after the RBE intake (B+R30 and R30 groups). The results of the operation taxonomic units (OTU) showed that the RBE intake increased the abundance of S24-7 while reducing the abundance of Lactobacillus (Figure 3B,C). We selected several bacteria that displayed significant changes during the OTU and LEfSe analyses to further understand the effects of BPA exposure and RBE supplementation on the succession of intestinal microbiota. Figure 3D shows that BPA exposure increased the abundance of Prevotella, Clostridium perfringens, and Clostridium ruminantiums, while RBE supplementation reduced the abundance of Lactobacillus and Prevotella and reduced the abundance of Clostridium perfringens and Clostridium ruminantiums to normal levels. In addition, the B+R30 group showed an increased abundance of Ruminococcus and Adlercreutzia. In contrast, our correlation analysis, which was performed to examine the microbiota and plasma biochemical markers (Figure 3E), revealed that the abundance of Lactobacillus was positively correlated with TG concentration and LW, while the abundance of Adlercreutzia was negatively correlated with TG concentration and LW. In addition, we also found that an elevation of the abundance of Clostridium perfringens and Clostridium ruminantiums could increase the BW and LW of the hosts. Taken together, our results showed that exposure to BPA dysregulated intestinal microbiota; this effect was alleviated via RBE supplementation, suggesting that RBE could effectively modulate intestinal microbiota.

The quantitative results for the faecal SCFAs in female offspring rats demonstrated that the exposure to BPA increased the faecal concentration of acetate, which could be reduced via RBE supplementation (B+R30) (see Table 2). However, the faecal concentrations of propionate and butyrate were not only obviously lower than that of acetate but also did not significantly differ between BPA-exposed and RBE-supplemented rat offspring. In particular, the R30 group showed a significantly higher faecal concentration of acetate than that of the $\mathrm{CN}$ group.

Table 2. SCFA concentrations in the faeces of female offspring rats.

\begin{tabular}{cccccc}
\hline SCFAs & \multirow{2}{*}{ CN } & R30 & BPA & B+R10 & B+R30 \\
\cline { 1 - 1 }$(\boldsymbol{\mu \text { mol/g Faeces } )}$ & & & & & \\
\hline Acetic acid & $21.01 \pm 2.03^{\mathrm{a}}$ & $28.51 \pm 3.54^{\mathrm{c}}$ & $31.67 \pm 2.93^{\mathrm{bc}}$ & $23.65 \pm 2.64^{\mathrm{ab}}$ & $17.75 \pm 1.15^{\mathrm{a}}$ \\
Propanoic acid & $3.50 \pm 0.30^{\mathrm{ab}}$ & $4.30 \pm 0.58^{\mathrm{ab}}$ & $3.62 \pm 0.21^{\mathrm{ab}}$ & $3.71 \pm 0.64^{\mathrm{a}}$ & $2.60 \pm 0.25^{\mathrm{b}}$ \\
Butanoic acid & $2.16 \pm 0.61^{\mathrm{a}}$ & $2.30 \pm 1.26^{\mathrm{a}}$ & $1.88 \pm 0.96^{\mathrm{a}}$ & $2.34 \pm 0.29^{\mathrm{a}}$ & $2.80 \pm 1.03^{\mathrm{a}}$ \\
\hline
\end{tabular}

${ }^{a-c}$ Values with different letters are specific to each group and show significant differences $(p<0.05)$. $\mathrm{CN}=$ control group; $\mathrm{R} 30=$ group administered with $30 \mathrm{mg} / \mathrm{kg} /$ day of RBE; BPA = group administered with $50 \mu \mathrm{g} / \mathrm{kg} /$ day of bisphenol A; BPA+R10 = group administered with $10 \mathrm{mg} / \mathrm{kg} /$ day of RBE and bisphenol A; BPA+R30 = group administered with $30 \mathrm{mg} / \mathrm{kg} /$ day of RBE and bisphenol A. Data are expressed as means $\pm \mathrm{SD}(n=4-8)$. 


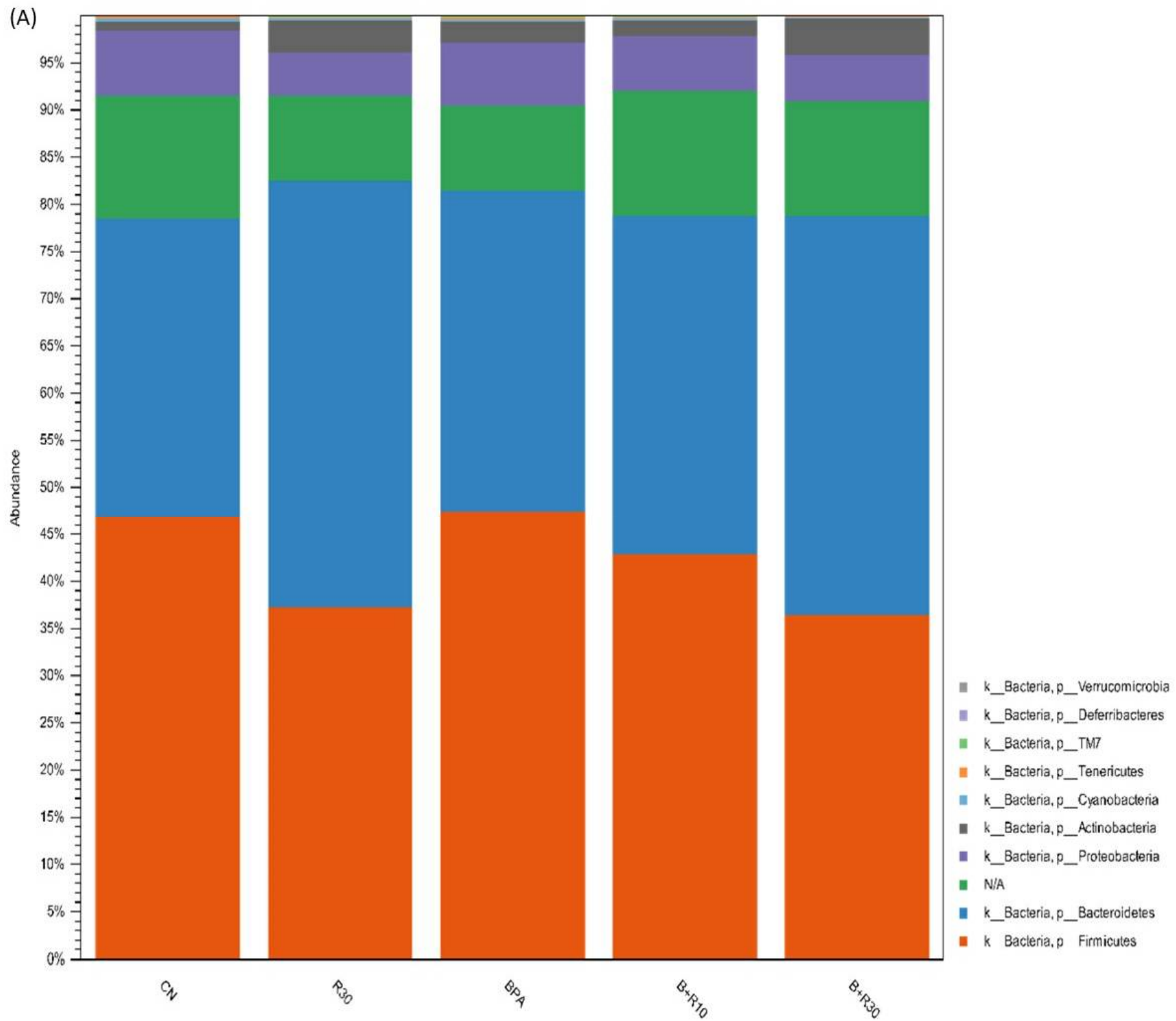

Figure 3. Cont. 
(B)

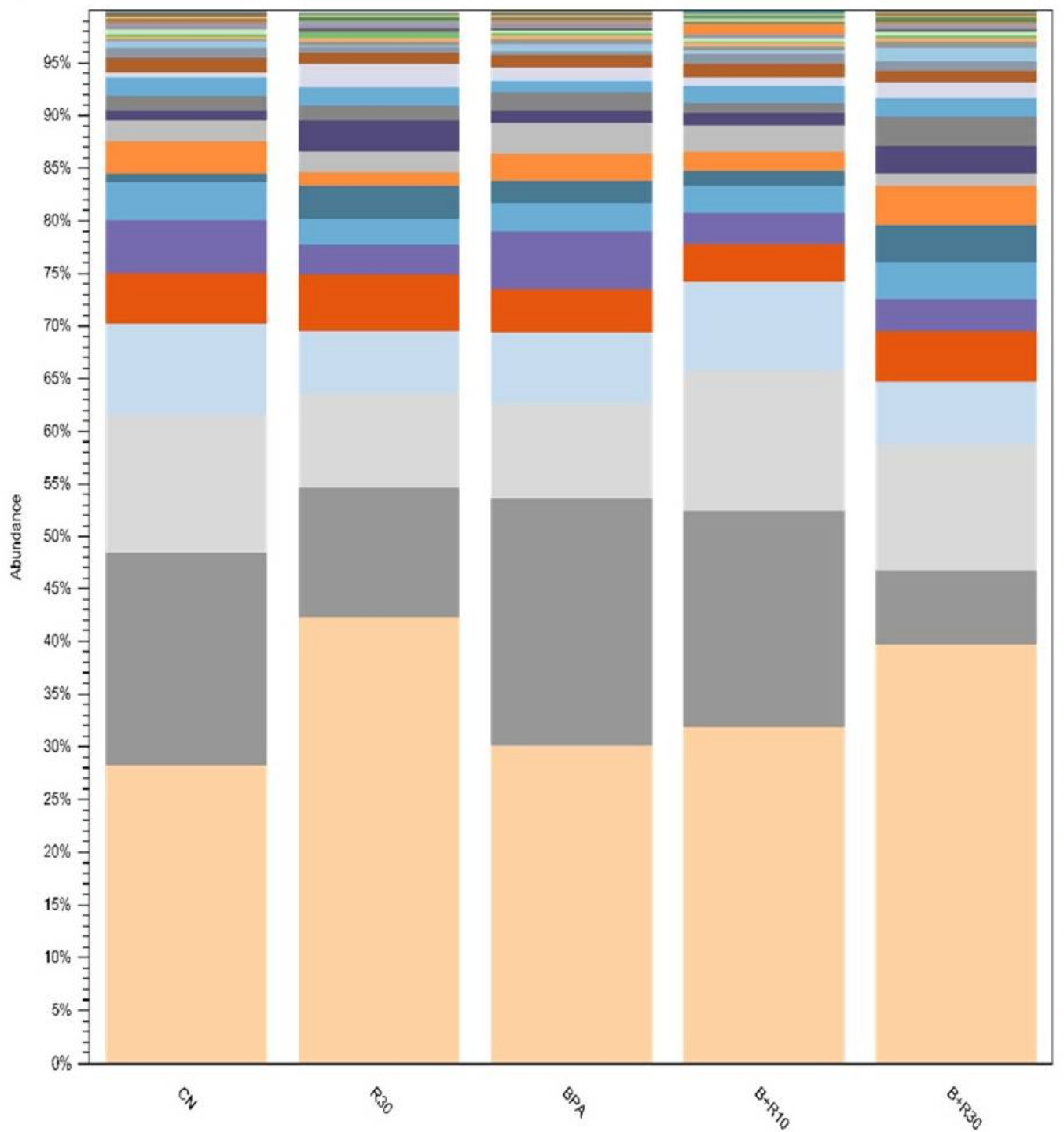

k Bacteria,p Bacteroidetes

II c_Bacteroidia.0_Bacteroidales.

f_Prevotellaceae, g_Prevotella

k_Bacteria, p_Firmicutes, c_Clostridia,

- Clostridiales $f$ Ruminococcaceae.

9_Ruminococcus

k Bacteria, p Actinobacteria

- C_Actinobacteria, 0_Bifidobacteriales,

f Bifidobacteriaceae, g Bifidobacterium

k_Bacteria, P_Firmicutes, c_Clostridia,

II O_Clostridiales,f_Ruminococcaceae,

9_Oscillospira

k_Bacteria, p_Proteobacteria,

- c_Betaproteobacteria, o_Burkholderiales,

f_Acaligenaceae, g_Sutterella

k_Bacteria, p_Firmicutes, c_Clostridia,

o_Clostridiales,f_Ruminococcaceae, g_

k_Bacteria, P_Firmicutes, c_Clostridia,

O_Clostridiales,f,g

11) N/A

k_Bacteria, P_Firmicutes, c_Bacili,

- Lactobacillales. $f$ Lactobacillaceae

g_Lactobacillus

k_Bacteria, p_Bacteroidetes.

c_Bacteroidia, 0_Bacteroidales,f_S24.7,

$g$

Figure 3. Cont. 
(C)

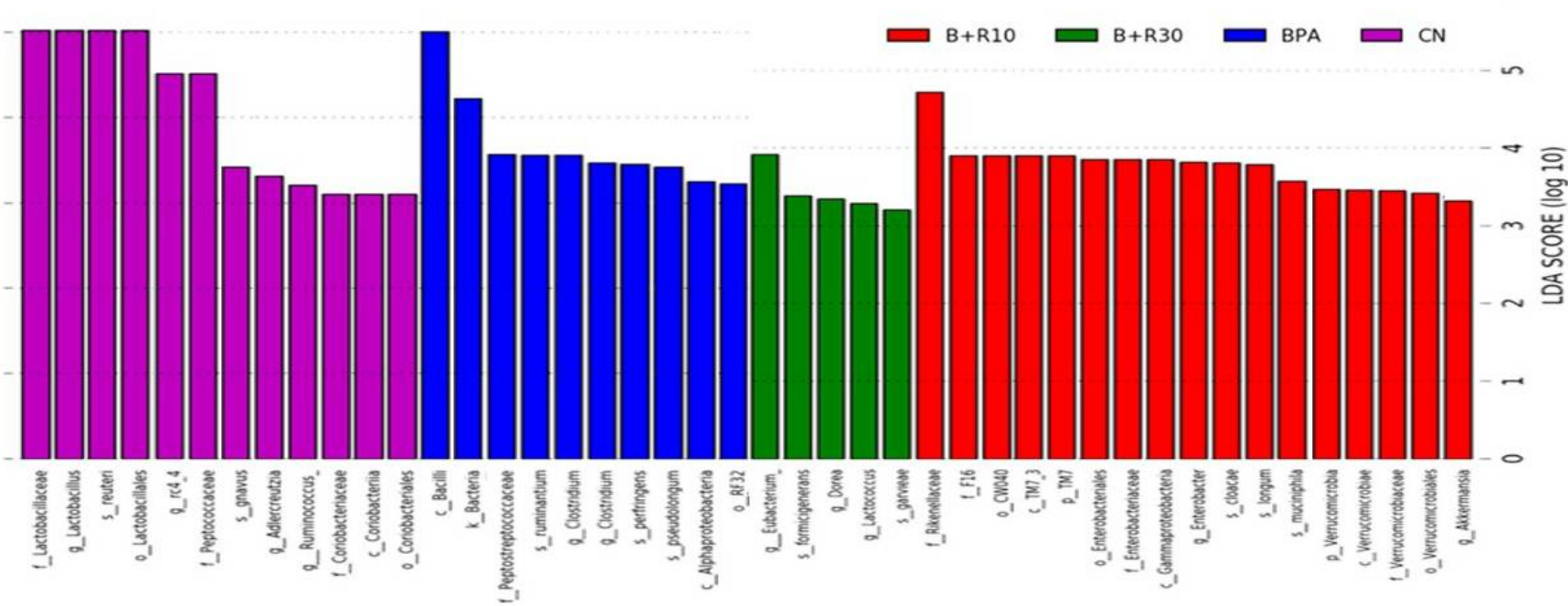

(D)
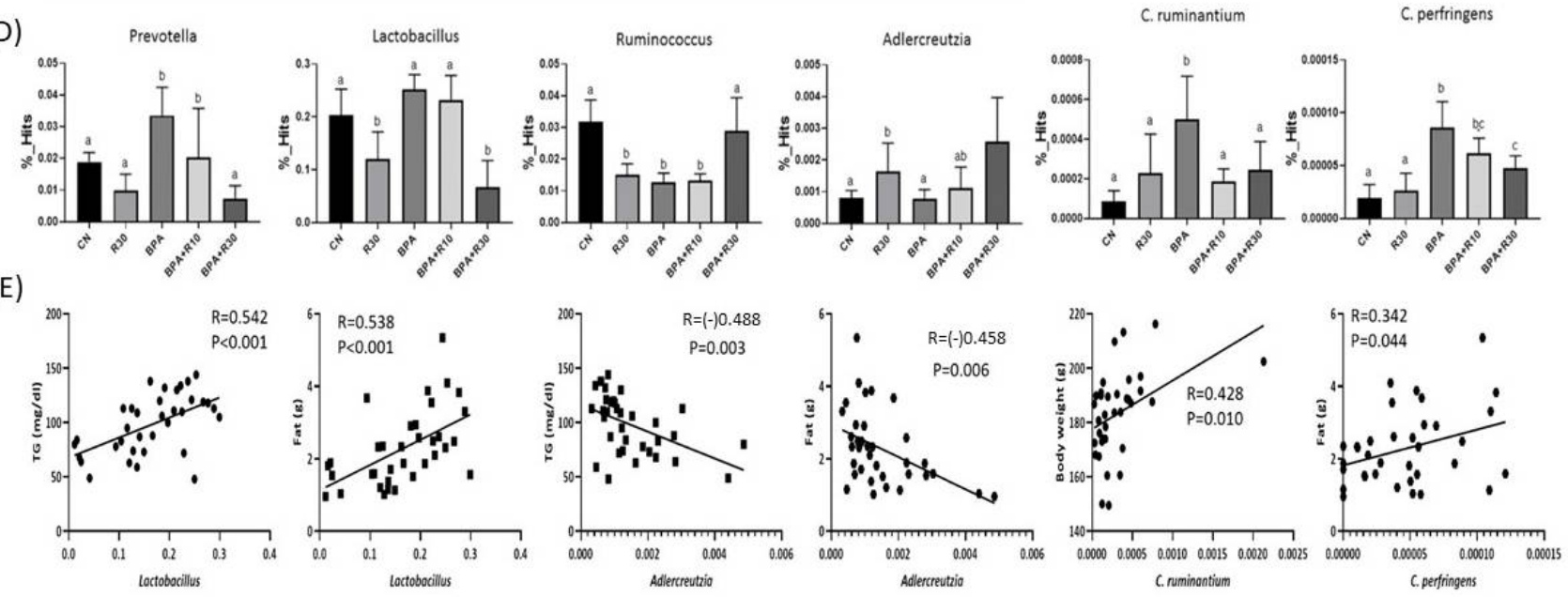

Figure 3. Effects of BPA and RBE on the gut microbiota of female offspring rats. (A) The gut bacterial composition at the phylum level. (B,C) Biomarker taxons generated from the LEfSe analysis (LDA > 3). (D) Comparison of the growth and decline of specific strains with significant changes in the OTU and LEfSe analyses. (E) Correlation analysis. ${ }^{a, b}$ Values with different letters are specific to each group and show significant differences $(p<0.05)$. $\mathrm{CN}=$ control group; $\mathrm{R} 30=$ group administered with $30 \mathrm{mg} / \mathrm{kg} /$ day of RBE; BPA = group administered with $50 \mu \mathrm{g} / \mathrm{kg} /$ day of bisphenol A; BPA+R10 = group administered with $10 \mathrm{mg} / \mathrm{kg} /$ day of RBE and bisphenol A; BPA+R30 = group administered with $30 \mathrm{mg} / \mathrm{kg} /$ day of RBE and bisphenol A. Data are expressed as means $\pm \mathrm{SD}(n=4-8)$.

\section{Discussion}

\subsection{RBE Suppressed BPA-Induced Obesity}

Numerous previous studies have shown that low-dose exposure to BPA during pregnancy and at the developmental stage can cause obesity [50,51]. Desai et al. (2018) reported that BPA in pregnant women can enter foetuses through the placenta and blood and can induce the differentiation of hypothalamic neurons in offspring, resulting in a higher number of appetite-promoting AgRP and NPY neurons, which cause obesity in the offspring [52]. BPA exposure also upregulated the expression of adipogenesis factors (e.g., leptin, $\mathrm{PPAR} \gamma, \mathrm{AP} 2$, and $\mathrm{C} / \mathrm{EBP} \alpha$ ), which accelerated the proliferation and differentiation of adipocytes [53,54]. Here, we found that the RBE intervention improved the BW and LW of female offspring rats with perinatal BPA exposure. As RBE can be hydrolysed by pancreatic lipases into RSV and butyrate in the intestine [40], orally administered RBE not 
only can demonstrate effects similar to those of RSV but also can prolong the absorption of RSV in the gastrointestinal tract, thereby extending its resident time in the blood. Liu et al. (2020) reported that maternal RSV intervention can prevent the adiposity programmed by maternal and postnatal HFHS diets by inducing metabolic lipid modulation [55]. This study indicates a distinct reprogramming role of the effects of maternal RSV supplements against obesity. RSV treatment prevented leptinaemia and increased p-STAT3 (signal transducer and activator of transcription 3) content in the hypothalamus with no changes in SOCS3 (suppressor of cytokine signalling 3), suggesting an improvement in leptin signalling [56]. Collectively, the data suggest that RSV could reverse hyperleptinemia and improve central leptin action in adult offspring from HF mothers, thus attenuating obesity.

Alway et al. (2017) reported that resveratrol may be useful in enhancing both cellular and functional changes that are common in sarcopenia in order to improve health outcomes in older men and women [57]. RSV supplementation improved muscle mass during reloading after hindlimb suspension and increased the cross-sectional area of type IIA and IIB fibres in response to reloading after hindlimb suspension [58]. Salomão et al. (2019) reported that, in combination with exercise, RSV was beneficial for muscle growth and metabolism, as it increased the expression levels of genes related to muscle anabolism and oxidative metabolism decreased catabolic gene expression [59]. Notably, all of these changes occurred together with muscular hypertrophy and increased body weight. Although RSV can regulate energy metabolism via the AMPK/SIRT1 pathway and is associated with adipogenesis [25], it remains unknown whether RSV can enter the bodies of offspring in trace amounts. Darby et al. (2019) reported that RSV intake during pregnancy enhanced the placental utilization of NO, resulting in vasodilation and improvements in the placental blood flow. This increased the BW of foetuses by enhancing the nutrient and oxygen supply [35]. In other words, the weight gains among female offspring rats compared to the weights observed in the CN group in this study may be associated with improved placental blood flow.

In contrast, RBE potentially prevents blood lipid, cardiovascular, circulatory, and metabolic diseases in offspring. Our results (Table 1) showed that the plasma concentrations of TG, TC, and LDL in female offspring rats increased, while the plasma concentration of HDL decreased after the exposure to BPA. After being supplemented with RBE, female offspring rats in the $\mathrm{B}+\mathrm{R} 30$ group showed a decline in the plasma concentration of TG and LDL, as well as an increase in the production of HDL. HDL is indispensable for the transport of cholesterol. Upon contacting the surface of HDL particles, the free cholesterol in the blood is rapidly esterified by lecithin-cholesterol acyltransferase (LCAT) and encapsulated in the core of HDL particles for removal from blood circulation [60]. However, LDL, which is considered a risk factor for atherosclerosis, can elevate the blood concentrations of TG and TC. In addition, oxidized LDL can accumulate in blood vessels and exacerbate atherosclerosis [61]. Gingrich et al. (2020) reported that a healthy placenta is crucial for foetal development, and placental abnormalities may easily lead to the onset of cardiovascular diseases and metabolic abnormalities in the foetus [62]. We speculated that exposure to BPA increases the risk for cardiovascular disease in offspring, which may be associated with damages to the placenta caused by the perinatal BPA exposure [62]. As mentioned earlier, RSV can improve the antioxidant defence and NO utilization in the placenta, thereby alleviating the oxidative damage caused by pregnancy complications, such as gestational diabetes, maternal obesity, placental abnormalities, and pre-eclampsia [35]. Based on our results, we infer that perinatal supplementation with RBE signifies the involvement of RSV in the alleviation of damages caused by BPA. Compared with the bioavailability of RSV in the body, RBE can significantly suppress associated injuries at a lower dose [38].

In addition, the expression of leptin (Table 1) in female offspring rats was upregulated after exposure to BPA. The expression of leptin returned to the normal level (similar to the $\mathrm{CN}$ group) after supplementation with $\mathrm{RBE}(\mathrm{B}+\mathrm{R} 10$ and $\mathrm{B}+\mathrm{R} 30$ groups $)(p>0.05)$. However, the R30 group showed a significantly higher level of leptin than the CN group $(p<0.05)$. Administration with RSV alone can increase the concentration of leptin in the 
body and reduce the elevation of the leptin level and the onset of leptin resistance, which are attributed to obesity or a high-cholesterol diet [63]. Leptin is secreted by adipocytes. Rönn et al. [64] showed that BPA exposure is positively correlated with the serum concentrations of leptin and adiponectin, but has no association with LW, indicating that BPA may interfere with the endocrine function of adipocytes and cause hormonal imbalances. Therefore, we speculated that supplementation with RBE can suppress BPA-induced abnormalities.

Previous studies have shown that PPAR $\gamma$ regulation can be mediated via the ERK1/2 pathway and phosphorylation of PPAR $\gamma$ is involved in insulin sensitivity [65]. Somm et al. [34] reported that exposure to BPA during pregnancy can result in an increase in parametrial white adipose tissue (PWAT) weight in female offspring rats. The expression of PPAR $\gamma, \mathrm{C} / \mathrm{EBP} \alpha$, and LPL was upregulated in abdominal adipocytes of adult female rats. Masuno et al. (2001) reported that BPA can increase the activity of LPL and the accumulation of TG in 3T3-L1 cells, leading to its differentiation into adipocytes with larger lipid droplets [66]. The staining of tissue sections in this study also yielded similar results (Figures 1 and 2). BPA increased the size of adipocytes and the thickness of subcutaneous fat tissue, while RBE supplementation (B+R10, B+R30, and R30 groups) significantly reversed the effects of BPA $(p<0.05)$. Li et al. (2017) [67] reported that SIRT1, phospho-ERK1/2, and phospho-PPAR $\gamma$, adiponectin and BDNF were all dysregulated in rats placed in $\mathrm{HH}$ group (maternal high-fat diet + postnatal high-fat diet); administration of resveratrol restored the expression and regulation of these molecules. Their results suggest that maternal high-fat diet during pregnancy and/or lactation sensitizes the offspring to the adverse effects of a subsequent high-fat diet on hippocampal function; however, administration of resveratrol is demonstrated to be beneficial in rescuing these effects [67]. Although there was a statistical difference in R30 compared with the control group, the data showed only a slight difference. We surmised that the R30 group could be related to the offspring's hemoperfusion [35] during the perinatal period, resulting in better activity and higher food intake. However, the specifics of the possible reasons still need to be further studied and discussed. Although RBE has not yet been extensively studied and its metabolic mechanism in the body remains unknown, our data confirmed that RBE can attenuate obesity caused by BPA exposure in offspring. Such a phenomenon may be attributed to the interference of RBE with the BPA-induced differentiation of adipocytes or its direct effects on the metabolism of adipocytes.

\subsection{The Relationship between the Suppression of Obesity by RBE and Intestinal Microbiota}

Here, the rats were subjected to perinatal BPA exposure to observe the effects of RBE supplementation on obesity-related indicators and intestinal microbiota in their female offspring in order to better understand the potential application of RBE in the future. Accumulating evidence has demonstrated that intestinal microbiota and their metabolites are closely associated with the onset of obesity and metabolic abnormalities in hosts [68]. Intestinal microbiota regulate the energy metabolism of the host and secrete metabolites to affect the health of the host. Therefore, diet-mediated modulation of intestinal microbiota is an important and feasible approach for the improvement of health and disease prevention. Our study revealed that (Figure 3A) the abundance of Bacteroidetes increased significantly, while the abundance of Firmicutes showed a decreasing trend after RBE supplementation. In contrast, Figure 3B,C shows that RBE intake can increase the abundance of S24-7 and decrease the abundance of Lactobacillus.

Li et al. (2021) reported that the Firmicutes/Bacteroidetes (F/B) ratio in the human intestines is associated with obesity, as obese patients had lower F/B ratios than normal individuals [42]. Li et al. (2018) found that a high-fat diet (HFD) can reduce the abundance of S24-7 and Lactobacillus in the intestines of mice [69]. Serino et al. (2012) reported that treatment with prebiotic gluco-oligosaccharide (GOS) can effectively restore the abundance of S24-7 and Lactobacillus after their reduction due to the HFD [70]. In addition, supplementation with RSV can alleviate the dysregulation of intestinal microbiota caused by an HFD and increase the abundance of Lactobacillus and Bifidobacterium in the intestines [71]. 
Previous studies about BPA exposure in the peri-pregnancy period showed significant effects on the offspring [28,29,72]; however, little research was performed to investigate the effects of the intestinal microbiota on the offspring. According to $\mathrm{Xu}$ et al. (2019), non-obese diabetic (NOD) mice (both female and male) that were born with exposure to BPA $(300 \mu \mathrm{g} / \mathrm{kg} \mathrm{BW})$ during the peri-pregnancy period did not show significant changes in the Firmicutes/Bacteroidetes (F/B) ratio [73]. Our study also showed a similar finding (see Figure 3A). Although the F/B ratios in the BPA and CN groups showed no significant differences in our study, metabolic abnormalities in female offspring induced by BPA exposure during the peri-pregnancy period were still present (also see $[28,29,72])$. In the present study, RBE significantly changed the intestinal microflora of the offspring (the F/B ratio decreased) (see Figure 3A). Based on this important finding, we speculate that BPA affected the slow body-fat metabolism of the female offspring and caused obesity, and it could also be possible that the intestinal flora of the female offspring adjusted to return the lipid metabolism to normal because of the RBE. The related physiological metabolic pathways need to be further clarified in the future.

RBE can be catabolized into RSV and butyrate [40]. However, the outcomes of RSV ingestion in pregnant women may differ from those in non-pregnant women. In particular, the intestinal microbiota in the offspring are mainly derived from the maternal microbiota, but the composition of the intestinal microbiota in infants is directly affected by childbirth delivery methods, postnatal diets, and the postnatal environment [74]. Huang et al. [75] showed that RSV supplementation could not alleviate the reduction in the abundance of Lactobacillus in offspring caused by prenatal and postnatal HFDs. Zha et al. (2020) revealed that the offspring of normal mice treated with $40 \mathrm{mg} / \mathrm{kg} /$ day of RSV during pregnancy displayed a decreasing trend in the abundance of Lactobacillus in their intestinal tracts [76]. The results of these previous studies were consistent with those of this study (Figure 3B,C), i.e., the results of the operational taxonomic units (OTUs) showed that RBE intake can increase the abundance of S24-7 and decrease the abundance of Lactobacillus. Animal studies on RBE have rarely been reported, and no perinatological studies demonstrating the effects of perinatal supplementation of RBE have been published. Therefore, it is not easy to explore the effects of RBE or its metabolites on obesity, physiology, biochemistry, and intestinal microbiota in female offspring rats without sufficient references.

The results of this study (Figure 3D) revealed that BPA exposure increased the abundance of Prevotella, Clostridium perfringens, and Clostridium ruminantiums. Treatment with RBE decreased the abundance of Lactobacillus and Prevotella and reduced the abundance of Clostridium perfringens and Clostridium ruminantiums to normal levels. In addition, the female offspring rats in the B+R30 group showed an increased abundance of Ruminococcus and Adlercreutzia. Chronic inflammation and arthritis are associated with Prevotella, which induces inflammation by stimulating the production of IL-8, IL-6, and CCL20 through colonic epithelial cells $[77,78]$. Clostridium perfringens is believed to be associated with neuromyelitis optica (NMO) and autism. In the intestines, Clostridium perfringens can produce enterotoxins that damage the intestinal mucosa and result in malnutrition $[79,80]$. Therefore, based on our results and others' studies, we speculated that perinatal exposure to BPA could lead to the dysregulation of intestinal microbiota in female offspring rats, thereby increasing the risk for metabolic abnormalities and intestinal inflammation in offspring.

RBE supplementation can effectively attenuate the BPA-induced dysregulation of intestinal microbiota. In addition, it was found in the correlation analysis performed to examine plasma biochemical markers and the selected microbiota (Figure 3E) that the abundance of Lactobacillus had a positive correlation with TG concentration and LW. Although most Lactobacillus species exhibit an anti-obesity effect, a small proportion of Lactobacillus species may still trigger the onset of obesity and metabolic abnormalities in hosts [81]. In contrast, the abundance of Adlercreutzia was negatively correlated with TG concentration and LW. An increase in the abundance of Clostridium perfringens and Clostridium ruminantiums may increase the BW and LW of the hosts. Jiao et al. (2019) 
reported that blueberry polyphenol extract (PPE) exhibits a positive effect on HFD-induced obesity in C57BL/6J mice [82]. Mice fed with an HFD showed weight gain and an increased weight of their adipose tissues, as well as increased lipid metabolism disorders. In contrast, PPE suppressed weight gain and reduced the lipid metabolism to the normal level. Further analysis revealed that PPE altered the composition of the intestinal microbiota in C57BL/6J mice and regulated the abundance of certain bacteria (e.g., Adlercreutzia). Together, these results show that the HFD reduced the abundance of Adlercreutzia, whereas PPE significantly reduced the abundance of Adlercreutzia [82].

It is interesting to note that, in the SCFA analysis, the female offspring in the R30 group (supplemented with RBE alone) showed significantly reduced obesity and adipogenesis but significantly increased faecal levels of acetate. Overby and Ferguson (2021) reported that SCFAs derived from intestinal microbiota can regulate obesity and hypertension by promoting the development of microbiota in hosts [83]. In addition, the R30 group showed a significantly higher faecal concentration of acetate than that of the CN group (Table 2). Mojsak et al. (2020) reported an increase in the faecal concentration of acetate in obese and diabetic patients [84]. Perry et al. (2016) demonstrated that acetate acts on parasympathetic activity to increase food intake and support glucose-stimulated insulin secretion in a rodent model [85]. Thus, we speculate that the acetate content is related to the weight gain caused by R30 supplementation in female offspring rats. In summary, RBE certainly has potential effects in the treatment or regulation of abnormal metabolism in the offspring of mothers exposed to BPA. Continuous and in-depth research is required for a better understanding of the physiological metabolic mechanisms.

\section{Materials and Methods}

\subsection{Synthesis of Resveratrol Butyrate Ester}

Resveratrol butyrate ester (RBE) was synthesised according to the method described by Tain et al. [37,38]. First, resveratrol and butyrate were mixed with tetrahydrofuran, followed by the addition of N-ethyl-N'-(3-dimethylaminopropyl) carbodiimide (EDC) and 4-dimethylaminopyridine (DMAP). Then, the resulting mixture was subjected to esterification in the dark at room temperature for $48 \mathrm{~h}$. Subsequently, a large amount of distilled water was added to the reaction mixture, followed by filtration. The resulting precipitate was rinsed with alcohol to obtain RBE, which was subsequently freeze-dried and stored at $-20{ }^{\circ} \mathrm{C}$.

\subsection{Experimental Animals}

The design of this experiment referred to a series of $\mathrm{DOHaD}$ trials and proceeded with the principles of the 3Rs for animal experimentation from Tain et al. [23,24,26,86]. Each group of two pregnant female rats will give birth to an average of 20 offspring [87]. Fifteen-week-old pregnant Sprague Dawley (SD) rats (purchased from BioLASCO Taiwan Co., Ltd., Taipei City, Taiwan) were used to construct the experimental models in compliance with the "Guide for the Care and Use of Laboratory Animals" of the National Institutes of Health. This study was approved by the Laboratory Animal Committee of Kaohsiung University of Science and Technology (Approval No: 0108-AAAP-010). All animal experimentations were carried out in animal facilities accredited by the Association for Assessment and Accreditation of Laboratory Animal Care International (AAALAC). The rats were maintained with 12-h light/dark cycles at $25 \pm 1{ }^{\circ} \mathrm{C}$. The 15 -week-old pregnant SD rats were randomly divided into five groups: the control group $(\mathrm{CN}), \mathrm{R} 30$ group (administered with $30 \mathrm{mg} / \mathrm{kg}$ /day of RBE dissolved in $0.2 \mathrm{~mL}$ corn oil), BPA group (administered with $50 \mu \mathrm{g} / \mathrm{kg} /$ day of BPA dissolved in $0.2 \mathrm{~mL}$ corn oil), BPA+R10 group (administered with $50 \mu \mathrm{g} / \mathrm{kg} /$ day and $10 \mathrm{mg} / \mathrm{kg} /$ day of BPA and RBE, respectively), and $\mathrm{BPA}+\mathrm{R} 30$ group (administered with $50 \mu \mathrm{g} / \mathrm{kg} /$ day and $30 \mathrm{mg} / \mathrm{kg} /$ day of BPA and RBE, respectively). The dose of BPA used here was based on a previous study [72,88]. RBE is a novel synthesis compound, the dose designed in this study referenced the dose used in RSV related studies $[72,89,90]$. Starting from the sixth day after pregnancy, the rats were 
subjected to gavage feeding with BPA and/or RBE for 36 consecutive days (including the first 21 days of lactation). Each group of two pregnant female rats gave birth to $14(\mathrm{CN})$, 16 (R30), 13 (BPA), 16 (B+R10), 17 (B+R30) offspring, respectively. Subsequently, their female offspring rats ( $n=4-8$ per group) were fed with a regular diet, which comprised $52 \%$ carbohydrates, $23.5 \%$ proteins, $4.5 \%$ fats, $10 \%$ ash, and $8 \%$ fibres (Fwusow Taiwan Co., Ltd., Taichung, Taiwan) [72]. The female offspring rats were euthanised at the age of 50 days to harvest their blood samples in tubes containing heparin, abdominal fat, and abdominal skin muscle tissues, as well as intestinal faeces, which were then stored at $-80^{\circ} \mathrm{C}$ for subsequent analyses. Only female offspring were selected from each litter for subsequent experiments to avoid experimental errors attributed to gender differences. The abdominal white adipose tissues (WATs) were harvested and weighed on an electronic precision balance prior to storage in $10 \%$ formalin at $-80{ }^{\circ} \mathrm{C}$ for subsequent experiments.

\subsection{Plasma Biochemical and Hormonal Analysis}

Blood samples harvested from euthanised female offspring rats were centrifuged at $1500 \times g$ and $4{ }^{\circ} \mathrm{C}$ for $10 \mathrm{~min}$, and the resulting supernatant (plasma) was collected for subsequent experiments. In this study, the concentrations of triglycerides (TG), total cholesterol (TC), high-density lipoprotein (HDL), and low-density lipoprotein (LDL) were determined using the Free Fatty Acid Quantification Assay Kit (Abcam, Cambridge, UK) [91], the Cholesterol/Cholesteryl Ester Quantitation Assay Kit (Abcam, Cambridge, UK) [92], and the HDL and LDL/VLDL Cholesterol Assay Kit (Abcam, Cambridge, UK) [93], while the plasma concentration of leptin was measured using the Leptin Rat ELISA Kit (Thermo Fisher Scientific, Waltham, MA, USA) [94] according to the manufacturer's instructions.

\subsection{Histopathology}

Adipose and subcutaneous tissues harvested from each female offspring rat were immersed in $10 \%$ formalin and then dehydrated with a continuous gradient of alcohol. After that, both samples were rinsed with xylene, embedded in paraffin, and divided into sections of approximately $5 \mu \mathrm{m}$. The paraffin-embedded tissues were then rinsed with xylene and absolute alcohol, followed by rehydration with a continuous gradient of alcohol. Subsequently, each section was stained with Mayer's haematoxylin solution and counterstained with eosin. After dehydration with alcohol and rinsing with xylene, each section was scanned with a panoramic slide scanner (MoticEasyScan), and the resulting images were analysed using Motic DS Assistant (4K).

\subsection{Metagenomics Analysis}

Faecal DNA was extracted with the QIAmp Fast DNA Stool Mini Kit (Qiagen, Hilden, Germany) according to the manufacturer's instructions. The DNA concentration was assessed by a NanoDrop 2000 (O.D. 260/280: 1.7-2.2, Conc. > $50 \mathrm{ng} / \mu \mathrm{L}$; Thermo Scientific, Waltham, MA, USA) with $10 \times$ dilution (final conc.: $4-6 \mathrm{ng} / \mu \mathrm{L}$ ) and with an elution buffer. The library was constructed using the standard V3-V4 region of the 16S ribosomal RNA gene. PCR was performed using the KAPA HiFi hotstart readymix (Roche, Indianapolis, IN, USA) and was purified with AMPure XP magnetic beads (Beckman Coulter, Brea, CA, USA). The quality of the amplified PCR product was assessed with a Fragment Analyzer (Advanced Analytical, Ankeny, IA, USA) and was quantified by a Qubit 3.0 Fluorometer. Then, the amplicons were sequenced on a MiSeq platform (Illumina, San Diego, CA, USA) with paired-end reads $(2 \times 300 \mathrm{nt})$ and at least 100,000 reads of every sample.

The raw paired-end reads were trimmed, and those that passed the quality filters were clustered into operational taxonomic units (OTUs) at $\geq 97 \%$ similarity with the GreenGene Database (v13.8). The taxonomic (relative abundance, heatmap), alpha diversity (Shannon index, Venn diagram), and beta diversity (PCoA, phylogenetic curve) characteristics of the OTUs were analysed with Basespace (Illumina, San Diego, CA, USA), the CLC genomics workbench (Qiagen, Hilden, Germany), and GraphPad Prism 8 (GraphPad Software, San Diego, CA, USA). The abundance of bacteria (linear discriminant analysis effect 
size, LEfSe) and associated functions (Phylogenetic Investigation of Communities by Reconstruction of Unobserved States, PICRUSt) were assessed on the Galaxy/Hutlab website (http:/ / huttenhower.sph.harvard.edu/galaxy/) (accesed data on 29 June 2021). A $p$-value of less than 0.05 was considered statistically significant.

\subsection{Quantification of Faecal SCFAs}

To quantify the faecal and colonic content of SCFAs, fresh intestinal contents were freeze-dried before weighing, and then the SCFAs were quantified as reported in the previous study [95]. After that, the mixture was centrifuged at $15,000 \times \mathrm{g}$ and $4{ }^{\circ} \mathrm{C}$ for 10 min to obtain the supernatant for a subsequent GC/MS analysis with a DB-FFAP capillary column $(30 \mathrm{~m} \times 0.25 \mathrm{~mm} \times 0.25 \mu \mathrm{m})$. Injection was performed at $240{ }^{\circ} \mathrm{C}$; the injection volume was $1 \mu \mathrm{L}$ with a split ratio of 5:1. The identities of compounds were determined by matching their mass spectra with GC/MS databases. Each peak identified via MS spectral matching exhibited a unique retention time (RT) and matching rate in the qualitative analysis (QUAL).

\subsection{Statistical Analyses}

A statistical analysis was conducted with a one-way analysis of variance (ANOVA) and Duncan's test. Significant differences were set at $p<0.05$. All statistical analyses were performed using the SPSS (version 12.0, St. Armonk, NY, USA) software.

\section{Conclusions}

In this study, rats were exposed to BPA during the perinatal period to observe the effects of RBE supplementation on obesity-related indicators and intestinal microbiota in their female offspring to better understand the potential application of RBE. The results demonstrated that RBE supplementation can alleviate BPA-induced weight gain and body fat accumulation, optimise the concentration of blood-lipid-related markers, significantly reduce the Firmicutes/Bacteroidetes (F/B) ratio and the abundance of Lactobacillus, and increase the abundance of S24-7. In addition, RBE supplementation can also regulate the intestinal concentration of acetate in female offspring rats. In summary, RBE can suppress BPA-induced obesity in female offspring rats and exhibits excellent modulatory activity in intestinal microbiota, with potential applications in perinatological research. In the future, we will clarify the metabolism of RBE in the digestive systems of animals and its haemodynamics after absorption to further understand the potential of RBE in future applications.

Author Contributions: Conceptualization, M.-K.S. and Y.-L.T.; data curation, Y.-L.T. and C.-Y.H.; formal analysis, M.-K.S. and Y.-L.T.; funding acquisition, S.K.C.C. and C.-Y.H.; investigation, Y.-T.Y.; methodology, M.-K.S., Y.-W.C., Y.-T.Y., and J.-X.L.; project administration, C.-Y.H.; resources, Y.-W.C.; software, Y.-W.C. and J.-X.L.; supervision, W.-H.H., S.K.C.C., and C.-Y.H.; validation, W.-H.H.; visualization, Y.-W.C. and W.-H.H.; writing — original draft, M.-K.S.; writing—review and editing, S.K.C.C. and C.-Y.H. All authors have read and agreed to the published version of the manuscript.

Funding: This research was funded by the Ministry of Science and Technology, Republic of China (grant Nos. 108-2221-E-992-046; 109-2221-E-992-051 and 110-2320-B-992-001-MY3), Kaohsiung Chang Gung Memorial Hospital, Taiwan (grant No. CORPG8L0301), and USDA-ARS SCA 5860667081.

Institutional Review Board Statement: Not applicable.

Informed Consent Statement: Not applicable.

Data Availability Statement: Not applicable.

Conflicts of Interest: The authors declare no conflict of interest.

Sample Availability: Samples of the compounds are available from the authors Chih-Yao Hou. 


\section{References}

1. Pelch, K.; Wignall, J.A.; Goldstone, A.E.; Ross, P.K.; Blain, R.B.; Shapiro, A.J.; Holmgren, S.D.; Hsieh, J.H.; Svoboda, D.; Auerbach, S.S.; et al. A scoping review of the health and toxicological activity of bisphenol A (BPA) structural analogues and functional alternatives. Toxicology 2019, 424, 152235. [CrossRef]

2. Rahman, M.S.; Adegoke, E.O.; Pang, M.-G. Drivers of owning more BPA. J. Hazard. Mater. 2021, 417, 126076. [CrossRef]

3. Moon, S.; Yu, S.H.; Lee, C.B.; Park, Y.J.; Yoo, H.J.; Kim, D.S. Effects of bisphenol A on cardiovascular disease: An epidemiological study using National Health and Nutrition Examination Survey 2003-2016 and meta-analysis. Sci. Total Environ. $2021,763$. [CrossRef] [PubMed]

4. Engin, A.B.; Engin, A. The effect of environmental Bisphenol A exposure on breast cancer associated with obesity. Environ. Toxicol. Pharmacol. 2021, 81. [CrossRef]

5. Lee, I.; Park, Y.J.; Kim, M.J.; Kim, S.; Choi, S.; Park, J.; Cho, Y.H.; Hong, S.; Yoo, J.; Park, H.; et al. Associations of urinary concentrations of phthalate metabolites, bisphenol A, and parabens with obesity and diabetes mellitus in a Korean adult population: Korean National Environmental Health Survey (KoNEHS) 2015-2017. Environ. Int. 2021, 146, 106227. [CrossRef] [PubMed]

6. Angle, B.M.; Do, R.P.; Ponzi, D.; Stahlhut, R.W.; Drury, B.E.; Nagel, S.C.; Welshons, W.V.; Besch-Williford, C.L.; Palanza, P.; Parmigiani, S.; et al. Metabolic disruption in male mice due to fetal exposure to low but not high doses of bisphenol A (BPA): Evidence for effects on body weight, food intake, adipocytes, leptin, adiponectin, insulin and glucose regulation. Reprod. Toxicol. 2013, 42, 256-268. [CrossRef]

7. Rancière, F.; Botton, J.; Slama, R.; Lacroix, M.Z.; Debrauwer, L.; Charles, M.A.; Roussel, R.; Balkau, B.; Magliano, D.J.; Balkau, B.; et al. Exposure to bisphenol a and bisphenol s and incident type 2 diabetes: A case-cohort study in the French cohort D.E.S.I.R. Environ. Health Perspect. 2019, 127. [CrossRef] [PubMed]

8. Shu, L.; Meng, Q.; Diamante, G.; Tsai, B.; Chen, Y.-W.; Mikhail, A.; Luk, H.; Ritz, B.; Allard, P.; Yang, X. Prenatal bisphenol a exposure in mice induces multitissue multiomics disruptions linking to cardiometabolic disorders. Endocrinology 2019, 160, 409-429. [CrossRef]

9. Churchwell, M.I.; Camacho, L.; Vanlandingham, M.M.; Twaddle, N.C.; Sepehr, E.; Delclos, K.B.; Fisher, J.W.; Doerge, D.R. Comparison of life-stage-dependent internal dosimetry for bisphenol A, ethinyl estradiol, a reference estrogen, and endogenous estradiol to test an estrogenic mode of action in Sprague Dawley rats. Toxicol. Sci. 2014, 139, 4-20. [CrossRef]

10. Doerge, D.R.; Twaddle, N.C.; Vanlandingham, M.; Fisher, J.W. Pharmacokinetics of bisphenol A in neonatal and adult SpragueDawley rats. Toxicol. Appl. Pharmacol. 2010, 247, 158-165. [CrossRef] [PubMed]

11. Doerge, D.R.; Twaddle, N.C.; Vanlandingham, M.; Fisher, J.W. Pharmacokinetics of Bisphenol A in neonatal and adult CD-1 mice: Inter-species comparisons with Sprague-Dawley rats and rhesus monkeys. Toxicol. Lett. 2011, 207, 298-305. [CrossRef]

12. Doerge, D.R.; Twaddle, N.C.; Vanlandingham, M.; Fisher, J.W. Pharmacokinetics of bisphenol A in serum and adipose tissue following intravenous administration to adult female CD-1 mice. Toxicol. Lett. 2012, 211, 114-119. [CrossRef] [PubMed]

13. Thayer, K.A.; Doerge, D.R.; Hunt, D.; Schurman, S.H.; Twaddle, N.C.; Churchwell, M.I.; Garantziotis, S.; Kissling, G.E.; Easterling, M.R.; Bucher, J.R.; et al. Pharmacokinetics of bisphenol A in humans following a single oral administration. Environ. Int. 2015, 83, 107-115. [CrossRef]

14. Völkel, W.; Colnot, T.; Csanády, G.A.; Filser, J.G.; Dekant, W. Metabolism and kinetics of bisphenol a in humans at low doses following oral administration. Chem. Res. Toxicol. 2002, 15, 1281-1287. [CrossRef]

15. Völkel, W.; Kiranoglu, M.; Fromme, H. Determination of free and total bisphenol A in human urine to assess daily uptake as a basis for a valid risk assessment. Toxicol. Lett. 2008, 179, 155-162. [CrossRef] [PubMed]

16. Teeguarden, J.G.; Calafat, A.M.; Ye, X.; Doerge, D.R.; Churchwell, M.I.; Gunawan, R.; Graham, M.K. Twenty-four hour human urine and serum profiles of bisphenol A during high-dietary exposure. Toxicol. Sci. 2011, 123, 48-57. [CrossRef]

17. Teeguarden, J.G.; Twaddle, N.C.; Churchwell, M.I.; Yang, X.; Fisher, J.W.; Seryak, L.M.; Doerge, D.R. 24-h human urine and serum profiles of bisphenol A: Evidence against sublingual absorption following ingestion in soup. Toxicol. Appl. Pharmacol. 2015, 288, 131-142. [CrossRef]

18. Report on the two-phase public consultation on the draft EFSA scientific opinion on bisphenol A (BPA). EFSA Support. Publ. 2017, 12, 740E. [CrossRef]

19. Adegoke, E.O.; Rahman, M.S.; Pang, M.G. Bisphenols Threaten Male Reproductive Health via Testicular Cells. Front. Endocrinol. 2020, 11, 624. [CrossRef]

20. Kitamura, S.; Suzuki, T.; Sanoh, S.; Kohta, R.; Jinno, N.; Sugihara, K.; Yoshihara, S.; Fujimoto, N.; Watanabe, H.; Ohta, S. Comparative study of the endocrine-disrupting activity of bisphenol A and 19 related compounds. Toxicol. Sci. 2005, 84, 249-259. [CrossRef]

21. Rahman, M.S.; Kwon, W.S.; Yoon, S.J.; Park, Y.J.; Ryu, B.Y.; Pang, M.G. A novel approach to assessing bisphenol-A hazards using an in vitro model system. BMC Genom. 2016, 17, 1-12. [CrossRef]

22. Beausoleil, C.; Emond, C.; Cravedi, J.P.; Antignac, J.P.; Applanat, M.; Appenzeller, B.M.R.; Beaudouin, R.; Belzunces, L.P.; Canivenc-Lavier, M.C.; Chevalier, N.; et al. Regulatory identification of BPA as an endocrine disruptor: Context and methodology. Mol. Cell. Endocrinol. 2018, 475, 4-9. [CrossRef] [PubMed]

23. Tain, Y.-L.; Chan, J.Y.H.; Lee, C.-T.; Hsu, C.-N. Maternal melatonin therapy attenuates methyl-donor diet-induced programmed hypertension in male adult rat offspring. Nutrients 2018, 10, 1407. [CrossRef] [PubMed] 
24. Tain, Y.-L.; Lin, Y.-J.; Chan, J.Y.H.; Lee, C.-T.; Hsu, C.-N. Maternal melatonin or agomelatine therapy prevents programmed hypertension in male offspring of mother exposed to continuous light. Biol. Reprod. 2017, 97, 636-643. [CrossRef]

25. Sergeyev, O.V.; Nikitin, A.I. Developmental origins of health and disease (DOHaD) and paternal origins of health and disease (POHaD). Multigenerational inheritance. Obstet. Gynecol. Reprod. 2019, 13, 326-336. [CrossRef]

26. Tain, Y.-L.; Lin, Y.-J.; Sheen, J.-M.; Yu, H.-R.; Tiao, M.-M.; Chen, C.-C.; Tsai, C.-C.; Huang, L.-T.; Hsu, C.-N. High Fat Diets Sex-Specifically Affect the Renal Transcriptome and Program Obesity, Kidney Injury, and Hypertension in the Offspring. Nutrients 2017, 9, 357. [CrossRef]

27. Mhaouty-Kodja, S.; Belzunces, L.P.; Canivenc, M.-C.; Schroeder, H.; Chevrier, C.; Pasquier, E. Impairment of learning and memory performances induced by BPA: Evidences from the literature of a MoA mediated through an ED. Mol. Cell. Endocrinol. 2018, 475, 54-73. [CrossRef]

28. Malaisé, Y.; Menard, S.; Cartier, C.; Gaultier, E.; Lasserre, F.; Lencina, C.; Harkat, C.; Geoffre, N.; Lakhal, L.; Castan, I.; et al. Gut dysbiosis and impairment of immune system homeostasis in perinatally-exposed mice to Bisphenol A precede obese phenotype development. Sci. Rep. 2017, 7. [CrossRef]

29. Reddivari, L.; Veeramachaneni, D.N.R.; Walters, W.A.; Lozupone, C.; Palmer, J.; Hewage, M.K.; Bhatnagar, R.; Amir, A.; Kennett, M.J.; Knight, R.; et al. Perinatal bisphenol a exposure induces chronic inflammation in rabbit offspring via modulation of gut bacteria and their metabolites. mSystems 2017, 2. [CrossRef]

30. Janesick, A.; Blumberg, B. Obesogens, stem cells and the developmental programming of obesity. Int. J. Androl. 2012, 35, 437-448. [CrossRef]

31. Vandenberg, L.N.; Colborn, T.; Hayes, T.B.; Heindel, J.J.; Jacobs, D.R.; Lee, D.H.; Shioda, T.; Soto, A.M.; vomSaal, F.S.; Welshons, W.V.; et al. Hormones and endocrine-disrupting chemicals: Low-dose effects and nonmonotonic dose responses. Endocr. Rev. 2012, 33, 378-455. [CrossRef]

32. Kundakovic, M.; Gudsnuk, K.; Franks, B.; Madrid, J.; Miller, R.L.; Perera, F.P.; Champagne, F.A. Sex-specific epigenetic disruption and behavioral changes following low-dose in utero bisphenol a exposure. Proc. Natl. Acad. Sci. USA 2013, 110, 9956-9961. [CrossRef] [PubMed]

33. Susiarjo, M.; Sasson, I.; Mesaros, C.; Bartolomei, M.S. Bisphenol A Exposure Disrupts Genomic Imprinting in the Mouse. PLoS Genet. 2013, 9, e1003401. [CrossRef]

34. Somm, E.; Schwitzgebel, V.M.; Toulotte, A.; Cederroth, C.R.; Combescure, C.; Nef, S.; Aubert, M.L.; Hüppi, P.S. Perinatal exposure to bisphenol A alters early adipogenesis in the rat. Environ. Health Perspect. 2009. [CrossRef] [PubMed]

35. Darby, J.R.T.; Mohd Dollah, M.H.B.; Regnault, T.R.H.; Williams, M.T.; Morrison, J.L. Systematic review: Impact of resveratrol exposure during pregnancy on maternal and fetal outcomes in animal models of human pregnancy complications-Are we ready for the clinic? Pharmacol. Res. 2019, 144, 264-278. [CrossRef]

36. Huang, X.; Li, X.; Xie, M.; Huang, Z.; Huang, Y.; Wu, G.; Peng, Z.; Sun, Y.; Ming, Q.; Liu, Y.; et al. Resveratrol: Review on its discovery, anti-leukemia effects and pharmacokinetics. Chem. Biol. Interact. 2019, 306, 29-38. [CrossRef] [PubMed]

37. Tain, Y.-L.; Chang, S.K.C.; Liao, J.-X.; Chen, Y.-W.; Huang, H.-T.; Li, Y.-L.; Hou, C.-Y. Synthesis of Short-Chain-Fatty-Acid Resveratrol Esters and Their Antioxidant Properties. Antioxidants 2021, 10, 420. [CrossRef] [PubMed]

38. Tain, Y.-L.; Jheng, L.-C.; Chang, S.K.C.; Chen, Y.-W.; Huang, L.-T.; Liao, J.-X.; Hou, C.-Y. Synthesis and Characterization of Novel Resveratrol Butyrate Esters That Have the Ability to Prevent Fat Accumulation in a Liver Cell Culture Model. Molecules 2020, 25, 4199. [CrossRef]

39. Wang, M.; Wichienchot, S.; He, X.; Fu, X.; Huang, Q.; Zhang, B. In vitro colonic fermentation of dietary fibers: Fermentation rate, short-chain fatty acid production and changes in microbiota. Trends Food Sci. Technol. 2019, 88, 1-9. [CrossRef]

40. Hu, X.-P.; Yin, F.-W.; Zhou, D.-Y.; Xie, H.-K.; Zhu, B.-W.; Ma, X.-C.; Tian, X.-G.; Wang, C.; Shahidi, F. Stability of resveratrol esters with caprylic acid during simulated in vitro gastrointestinal digestion. Food Chem. 2019, 276, 675-679. [CrossRef]

41. Wilkins, A.T.; Reimer, R.A. Obesity, early life gut microbiota, and antibiotics. Microorganisms 2021, 9, 413. [CrossRef] [PubMed]

42. Li, X.; Yang, L.; Xu, M.; Qiao, G.; Li, C.; Lin, L.; Zheng, G. Smilax china L. polyphenols alleviates obesity and inflammation by modulating gut microbiota in high fat/high sucrose diet-fed C57BL/6J mice. J. Funct. Foods 2021, 77, 104332. [CrossRef]

43. Koliada, A.; Syzenko, G.; Moseiko, V.; Budovska, L.; Puchkov, K.; Perederiy, V.; Gavalko, Y.; Dorofeyev, A.; Romanenko, M.; Tkach, S.; et al. Association between body mass index and Firmicutes/Bacteroidetes ratio in an adult Ukrainian population. BMC Microbiol. 2017, 17, 120. [CrossRef] [PubMed]

44. Shen, Z.H.; Zhu, C.X.; Quan, Y.S.; Yang, Z.Y.; Wu, S.; Luo, W.W.; Tan, B.; Wang, X.Y. Relationship between intestinal microbiota and ulcerative colitis: Mechanisms and clinical application of probiotics and fecal microbiota transplantation. World J. Gastroenterol. 2018, 24, 5-14. [CrossRef]

45. Abenavoli, L.; Scarpellini, E.; Colica, C.; Boccuto, L.; Salehi, B.; Sharifi-Rad, J.; Aiello, V.; Romano, B.; De Lorenzo, A.; Lzzo, A.A. Gut Microbiota and Obesity: A Role for Probiotics. Nutrients 2019, 11, 2690. [CrossRef]

46. Strakovsky, R.S.; Wang, H.; Engeseth, N.J.; Flaws, J.A.; Helferich, W.G.; Pan, Y.X.; Lezmi, S. Developmental bisphenol A (BPA) exposure leads to sex-specific modification of hepatic gene expression and epigenome at birth that may exacerbate high-fat diet-induced hepatic steatosis. Toxicol. Appl. Pharmacol. 2015, 284, 101-112. [CrossRef]

47. Lejonklou, M.H.; Dunder, L.; Bladin, E.; Pettersson, V.; Rönn, M.; Lind, L.; Waldén, T.B.; Lind, P.M. Effects of low-dose developmental bisphenol a exposure on metabolic parameters and gene expression in male and female fischer 344 rat offspring. Environ. Health Perspect. 2017, 125. [CrossRef] 
48. Yang, T.C.; Peterson, K.E.; Meeker, J.D.; Sánchez, B.N.; Zhang, Z.; Cantoral, A.; Solano, M.; Tellez-Rojo, M.M. Bisphenol A and phthalates in utero and in childhood: Association with child BMI z-score and adiposity. Environ. Res. 2017, 156, 326-333. [CrossRef]

49. Rubin, B.S.; Paranjpe, M.; DaFonte, T.; Schaeberle, C.; Soto, A.M.; Obin, M.; Greenberg, A.S. Perinatal BPA exposure alters body weight and composition in a dose specific and sex specific manner: The addition of peripubertal exposure exacerbates adverse effects in female mice. Reprod. Toxicol. 2017, 68, 130-144. [CrossRef]

50. vomSaal, F.S.; Nagel, S.C.; Coe, B.L.; Angle, B.M.; Taylor, J.A. The estrogenic endocrine disrupting chemical bisphenol A (BPA) and obesity. Mol. Cell. Endocrinol. 2012, 354, 74-84. [CrossRef]

51. Rubin, B.S.; Soto, A.M. Bisphenol A: Perinatal exposure and body weight. Mol. Cell. Endocrinol. 2009, 304, 55-62. [CrossRef]

52. Desai, M.; Ferrini, M.G.; Han, G.; Jellyman, J.K.; Ross, M.G. In vivo maternal and in vitro BPA exposure effects on hypothalamic neurogenesis and appetite regulators. Environ. Res. 2018. [CrossRef]

53. Murata, M.; Kang, J.-H. Bisphenol A (BPA) and cell signaling pathways. Biotechnol. Adv. 2018, 36, 311-327. [CrossRef]

54. Pu, Y.; Gingrich, J.D.; Steibel, J.P.; Veiga-Lopez, A. Sex-Specific Modulation of Fetal Adipogenesis by Gestational Bisphenol A and Bisphenol S Exposure. Endocrinology 2017, 158, 3844-3858. [CrossRef]

55. Liu, T.Y.; Yu, H.R.; Tsai, C.C.; Huang, L.T.; Chen, C.C.; Sheen, J.M.; Tiao, M.M.; Tain, Y.L.; Lin, I.C.; Lai, Y.J.; et al. Resveratrol intake during pregnancy and lactation re-programs adiposity and ameliorates leptin resistance in male progeny induced by maternal high-fat/high sucrose plus postnatal high-fat/high sucrose diets via fat metabolism regulation. Lipids Health Dis. 2020, 19, 1-13. [CrossRef]

56. Franco, J.G.; Dias-Rocha, C.P.; Fernandes, T.P.; Albuquerque Maia, L.; Lisboa, P.C.; Moura, E.G.; Pazos-Moura, C.C.; Trevenzoli, I.H. Resveratrol treatment rescues hyperleptinemia and improves hypothalamic leptin signaling programmed by maternal high-fat diet in rats. Eur. J. Nutr. 2016, 55, 601-610. [CrossRef] [PubMed]

57. Alway, S.E.; McCrory, J.L.; Kearcher, K.; Vickers, A.; Frear, B.; Gilleland, D.L.; Bonner, D.E.; Thomas, J.M.; Donley, D.A.; Lively, M.W.; et al. Resveratrol Enhances Exercise-Induced Cellular and Functional Adaptations of Skeletal Muscle in Older Men and Women. Journals Gerontol.-Ser. A Biol. Sci. Med. Sci. 2017, 72, 1595-1606. [CrossRef]

58. Bennett, B.T.; Mohamed, J.S.; Alway, S.E. Effects of resveratrol on the recovery of muscle mass following disuse in the plantaris muscle of aged rats. PLoS ONE 2013, 8, e83518. [CrossRef]

59. Salomão, R.A.S.; DePaula, T.G.; Zanella, B.T.T.; Carvalho, P.L.P.F.; daSilva Duran, B.O.; Valente, J.S.; deAlmeida Fantinatti, B.E.; Fernandes, A.A.; Barros, M.M.; Mareco, E.A.; et al. The combination of resveratrol and exercise enhances muscle growth characteristics in pacu (Piaractus mesopotamicus). Comp. Biochem. Physiol.-Part A Mol. Integr. Physiol. 2019, 235, 46-55. [CrossRef]

60. Nicholls, S.J.; Nelson, A.J. HDL and cardiovascular disease. Pathology 2019, 51, 142-147. [CrossRef]

61. Hirayama, S.; Miida, T. Small dense LDL: An emerging risk factor for cardiovascular disease. Clin. Chim. Acta 2012, 414, 215-224. [CrossRef] [PubMed]

62. Gingrich, J.; Ticiani, E.; Veiga-Lopez, A. Placenta Disrupted: Endocrine Disrupting Chemicals and Pregnancy. Trends Endocrinol. Metab. 2020, 31, 508-524. [CrossRef]

63. Jimoh, A.; Tanko, Y.; Ayo, J.O.; Ahmed, A.; Mohammed, A. Resveratrol increases serum adiponectin level and decreases leptin and insulin level in an experimental model of hypercholesterolemia. Pathophysiology 2018, 25, 411-417. [CrossRef] [PubMed]

64. Rönn, M.; Lind, L.; Örberg, J.; Kullberg, J.; Söderberg, S.; Larsson, A.; Johansson, L.; Ahlström, H.; Lind, P.M. Bisphenol A is related to circulating levels of adiponectin, leptin and ghrelin, but not to fat mass or fat distribution in humans. Chemosphere 2014, 112, 42-48. [CrossRef]

65. Rangwala, S.M.; Rhoades, B.; Shapiro, J.S.; Rich, A.S.; Kim, J.K.; Shulman, G.I.; Kaestner, K.H.; Lazar, M.A. Genetic modulation of PPARgamma phosphorylation regulates insulin sensitivity. Dev. Cell 2003, 5, 657-663. [CrossRef]

66. Masuno, H.; Kidani, T.; Sekiya, K.; Sakayama, K.; Shiosaka, T.; Yamamoto, H.; Honda, K. Bisphenol A in combination with insulin can accelerate the conversion of 3T3-L1 fibroblasts to adipocytes. J. Lipid Res. 2002. [CrossRef]

67. Li, S.-W.; Yu, H.-R.; Sheen, J.-M.; Tiao, M.-M.; Tain, Y.-L.; Lin, I.-C.; Lin, Y.-J.; Chang, K.-A.; Tsai, C.-C.; Huang, L.-T. A Maternal High-Fat Diet during Pregnancy and Lactation, in Addition to a Postnatal High-Fat Diet, Leads to Metabolic Syndrome with Spatial Learning and Memory Deficits: Beneficial Effects of Resveratrol. Oncotarget 2017, 8, 111998-112013. [CrossRef]

68. Bridgeman, S.C.; Northrop, W.; Melton, P.E.; Ellison, G.C.; Newsholme, P.; Mamotte, C.D.S. Butyrate generated by gut microbiota and its therapeutic role in metabolic syndrome. Pharmacol. Res. 2020, 160, 105174. [CrossRef]

69. Li, T.; Gao, J.; Du, M.; Mao, X. Milk fat globule membrane supplementation modulates the gut microbiota and attenuates metabolic endotoxemia in high-fat diet-fed mice. J. Funct. Foods 2018, 47, 56-65. [CrossRef]

70. Serino, M.; Luche, E.; Gres, S.; Baylac, A.; Bergé, M.; Cenac, C.; Waget, A.; Klopp, P.; Iacovoni, J.; Klopp, C.; et al. Metabolic adaptation to a high-fat diet is associated with a change in the gut microbiota. Gut 2012. [CrossRef]

71. Wang, P.; Gao, J.; Ke, W.; Wang, J.; Li, D.; Liu, R.; Jia, Y.; Wang, X.; Chen, X.; Chen, F.; et al. Resveratrol reduces obesity in high-fat diet-fed mice via modulating the composition and metabolic function of the gut microbiota. Free Radic. Biol. Med. 2020, 156, 83-98. [CrossRef]

72. Hsu, C.-N.; Lin, Y.-J.; Tain, Y.-L. Maternal Exposure to Bisphenol A Combined with High-Fat Diet-Induced Programmed Hypertension in Adult Male Rat Offspring: Effects of Resveratrol. Int. J. Mol. Sci. 2019, 20, 4382. [CrossRef]

73. Xu, J.; Huang, G.; Nagy, T.; Guo, T.L. Bisphenol A alteration of type 1 diabetes in non-obese diabetic (NOD) female mice is dependent on window of exposure. Arch. Toxicol. 2019, 93, 1083-1093. [CrossRef] 
74. Vandenplas, Y.; Carnielli, V.P.; Ksiazyk, J.; Luna, M.S.; Migacheva, N.; Mosselmans, J.M.; Picaud, J.C.; Possner, M.; Singhal, A.; Wabitsch, M. Factors affecting early-life intestinal microbiota development. Nutrition 2020, 78, 110812. [CrossRef]

75. Huang, Y.-C.; Huang, L.-T.; Sheen, J.-M.; Hou, C.-Y.; Yeh, Y.-T.; Chiang, C.-P.; Lin, I.-C.; Tiao, M.-M.; Tsai, C.-C.; Lin, Y.-J.; et al. Resveratrol treatment improves the altered metabolism and related dysbiosis of gut programed by prenatal high-fat diet and postnatal high-fat diet exposure. J. Nutr. Biochem. 2020, 75, 108260. [CrossRef]

76. Zha, C.; Xiao, H.; Song, B.; Zheng, C.; Yang, X.; Wang, W.; Wang, L. Resveratrol promotes mammary cell proliferation and antioxidation capacity during pregnancy and lactation in mice. J. Appl. Microbiol. 2020. [CrossRef]

77. Larsen, J.M. The immune response to Prevotella bacteria in chronic inflammatory disease. Immunology 2017.

78. Scher, J.U.; Sczesnak, A.; Longman, R.S.; Segata, N.; Ubeda, C.; Bielski, C.; Rostron, T.; Cerundolo, V.; Pamer, E.G.; Abramson, S.B.; et al. Expansion of intestinal Prevotella copri correlates with enhanced susceptibility to arthritis. eLife 2013, 2, e01202. [CrossRef]

79. Finegold, S.M.; Summanen, P.H.; Downes, J.; Corbett, K.; Komoriya, T. Detection of Clostridium perfringens toxin genes in the gut microbiota of autistic children. Anaerobe 2017, 45, 133-137. [CrossRef] [PubMed]

80. Cree, B.A.C.; Spencer, C.M.; Varrin-Doyer, M.; Baranzini, S.E.; Zamvil, S.S. Gut microbiome analysis in neuromyelitis optica reveals overabundance of Clostridium perfringens. Ann. Neurol. 2016. [CrossRef]

81. Cao, S.-Y.; Zhao, C.-N.; Xu, X.-Y.; Tang, G.-Y.; Corke, H.; Gan, R.-Y.; Li, H.-B. Dietary plants, gut microbiota, and obesity: Effects and mechanisms. Trends Food Sci. Technol. 2019, 92, 194-204. [CrossRef]

82. Jiao, X.; Wang, Y.; Lin, Y.; Lang, Y.; Li, E.; Zhang, X.; Zhang, Q.; Feng, Y.; Meng, X.; Li, B. Blueberry polyphenols extract as a potential prebiotic with anti-obesity effects on C57BL/6 J mice by modulating the gut microbiota. J. Nutr. Biochem. 2019, 64, 88-100. [CrossRef]

83. Overby, H.B.; Ferguson, J.F. Gut Microbiota-Derived Short-Chain Fatty Acids Facilitate Microbiota: Host Cross talk and Modulate Obesity and Hypertension. Curr. Hypertens. Rep. 2021, 23. [CrossRef]

84. Mojsak, P.; Rey-Stolle, F.; Parfieniuk, E.; Kretowski, A.; Ciborowski, M. The role of gut microbiota (GM) and GM-related metabolites in diabetes and obesity. A review of analytical methods used to measure GM-related metabolites in fecal samples with a focus on metabolites' derivatization step. J. Pharm. Biomed. Anal. 2020, 191, 113617. [CrossRef]

85. Perry, R.J.; Peng, L.; Barry, N.A.; Cline, G.W.; Zhang, D.; Cardone, R.L.; Petersen, K.F.; Kibbey, R.G.; Goodman, A.L.; Shulman, G.I. Acetate mediates a microbiome-brain- $\beta$-cell axis to promote metabolic syndrome. Nature 2016, 534, 213-217. [CrossRef] [PubMed]

86. Tain, Y.-L.; Chan, S.H.H.; Chan, J.Y.H. Biochemical basis for pharmacological intervention as a reprogramming strategy against hypertension and kidney disease of developmental origin. Biochem. Pharmacol. 2018, 153, 82-90. [CrossRef]

87. Otto, G.M.; Franklin, C.L.; Clifford, C.B. Chapter 4-Biology and Diseases of Rats. In Laboratory Animal Medicine: Third Edition; Elsevier Inc.: Amsterdam, The Netherlands, 2015; pp. 151-207. ISBN 9780124095274.

88. Wei, J.; Sun, X.; Chen, Y.; Li, Y.; Song, L.; Zhou, Z.; Xu, B.; Lin, Y.; Xu, S. Perinatal exposure to bisphenol A exacerbates nonalcoholic steatohepatitis-like phenotype in male rat offspring fed on a high-fat diet. J. Endocrinol. 2014, 222, 313-325. [CrossRef] [PubMed]

89. Chen, H.-E.; Lin, Y.-J.; Lin, I.-C.; Yu, H.-R.; Sheen, J.-M.; Tsai, C.-C.; Huang, L.-T.; Tain, Y.-L. Resveratrol prevents combined prenatal $\mathrm{N}^{\mathrm{G}}$-nitro-L-arginine-methyl ester (L-NAME) treatment plus postnatal high-fat diet induced programmed hypertension in adult rat offspring: Interplay between nutrient-sensing signals, oxidative stress and gut. J. Nutr. Biochem. 2019, 70, 28-37. [CrossRef]

90. Hsu, C.-N.; Lin, Y.-J.; Lu, P.-C.; Tain, Y.-L. Maternal resveratrol therapy protects male rat offspring against programmed hypertension induced by TCDD and dexamethasone exposures: Is it relevant to aryl hydrocarbon receptor? Int. J. Mol. Sci. 2018, 19, 2459. [CrossRef]

91. abcamFree Fatty Acid Quantification Assay Kit ab ab65341, Protocol Book Let. Available online: https://www.abcam.com/FreeFatty-Acid-Assay-Kit-Quantification-ab65341.html?pageNumber=2 (accessed on 29 June 2021).

92. abcamCholesterol/Cholesteryl Ester Quantitation Assay Kit ab65359, Protocol Book Let. Available online: Cholesterol/ CholesterylEhttps://www.abcam.com/ps/products/65/ab65359/documents/ab65359Cholesterol-CholesterylEsterQuantification kitprotocolv5(website).pdf (accessed on 2 April 2021).

93. abcamHDL and LDL/VLDL Cholesterol Assay Kit ab65390, Protocol Book Let. Available online: https://www.abcam. $\mathrm{com} / \mathrm{ps}$ /products/65/ab65390/documents/HDL-and-LDL-VLDL-Cholesterol-assay-protocol\%20(website).pdf (accessed on 29 June 2021).

94. ThermoFisher ScientificRat Leptin ELISA Kit KRC2281, Protocol Book Let. Available online: https:/ / assets.thermofisher.com/ TFS-Assets/LSG/manuals/MAN0004044_KRC2281_Rt_Leptin_ELISA_PI.pdf (accessed on 2 April 2021).

95. Wang, G.; Yu, Y.; Garcia-gutierrez, E.; Jin, X.; He, Y.; Wang, L.; Tian, P.; Liu, Z.; Zhao, J.; Zhang, H.; et al. Lactobacillus acidophilus jcm 1132 strain and its mutant with different bacteriocin-producing behaviour have various in situ effects on the gut microbiota of healthy mice. Microorganisms 2020, 8, 49. [CrossRef] 